\title{
Transcriptomic analysis reveals protein homeostasis breakdown in the coral Acropora millepora during hypo-saline stress
}

\author{
Catalina Aguilar 1,2,3,4 Jean-Baptiste Raina 1,5 Sylvain Fôret ${ }^{2,6}$, David C. Hayward ${ }^{6}$, Bruno Lapeyre ${ }^{7}$, \\ David G. Bourne ${ }^{1,8,9}$ and David J. Miller ${ }^{1,2^{*}}$
}

\begin{abstract}
Background: Coral reefs can experience salinity fluctuations due to rainfall and runoff; these events can have major impacts on the corals and lead to bleaching and mortality. On the Great Barrier Reef (GBR), low salinity events, which occur during summer seasons and can involve salinity dropping 10 PSU correlate with declines in coral cover, and these events are predicted to increase in frequency and severity under future climate change scenarios. In other marine invertebrates, exposure to low salinity causes increased expression of genes involved in proteolysis, responses to oxidative stress, and membrane transport, but the effects that changes in salinity have on corals have so far received only limited attention. To better understand the coral response to hypo-osmotic stress, here we investigated the transcriptomic response of the coral Acropora millepora in both adult and juvenile life stages to acute $(1 \mathrm{~h})$ and more prolonged ( $24 \mathrm{~h}$ ) exposure to low salinity.
\end{abstract}

Results: Differential gene expression analysis revealed the involvement of both common and specific response mechanisms in Acropora. The general response to environmental stressors included up-regulation of genes involved in the mitigation of macromolecular and oxidative damage, while up-regulation of genes involved in amino acid metabolism and transport represent specific responses to salinity stress.

Conclusions: This study is the first comprehensive transcriptomic analysis of the coral response to low salinity stress and provides important insights into the likely consequences of heavy rainfall and runoff events on coral reefs.

Keywords: Coral, Transcriptomics, Salinity stress, Endoplasmic reticulum, Amino acid metabolism

\section{Background}

Coral reefs are amongst the most diverse and complex of ecosystems and, as well as their biological significance, are of enormous social and economic importance [1]. However, they are experiencing long-term decline on a global scale due to overfishing, pollution, and climate change [2, 3]. Climate change is likely to be an increasingly significant cause of coral loss through thermal stress and ocean

\footnotetext{
* Correspondence: david.miller@jcu.edu.au

'AIMS@JCU and Department of Molecular and Cell Biology, James Cook University, Townsville, Queensland 4811, Australia

${ }^{2}$ ARC Centre of Excellence for Coral Reef Studies and Department of

Molecular and Cell Biology, James Cook University, Townsville, Queensland

4811, Australia

Full list of author information is available at the end of the article
}

acidification $[4,5]$, but also via increases in the frequency and intensity of tropical cyclones, which can expose coral reefs to more extreme and sudden salinity variations [6-8]. These conditions affect the Great Barrier Reef (GBR), where rain associated with tropical cyclones can lower the salinity of surface waters significantly (up to $10 \mathrm{PSU}$ ) [9], with these hypo-saline conditions sometimes prevailing for weeks [10]. Although the impacts of heavy rainfall can be correlated with coral decline on the GBR [11], the physiological effects of hypo-saline stress have not been thoroughly investigated. A few studies have described loss of Symbiodiniaceae and coral mortality following hyposaline stress events [12-14], but no data are available on the molecular response of corals during these events.

(c) The Author(s). 2019 Open Access This article is distributed under the terms of the Creative Commons Attribution 4.0 International License (http://creativecommons.org/licenses/by/4.0/), which permits unrestricted use, distribution, and 
Like many other marine invertebrates, corals are considered to be osmoconformers -their internal environment is near isotonic with the external environment - and can only tolerate a relatively narrow range of salinity (i.e. they are stenohaline). Our current understanding of osmoregulation processes in corals is largely derived from other marine invertebrates such as sea anemones and bivalves; in these organisms, small organic molecules and inorganic ions are used to prevent osmotic lysis $[15,16]$. These molecules, known as osmolytes, include free amino acids (FAAs), FAA derivates (taurine, glycine betaine), floridoside and other compounds such as dimethylsulfoniopropionate (DMSP) [17, 18]. In many cases, organisms use a variety of osmolytes and related species may use quite different mechanisms. For example, the sea anemone Metridium senile, and marine sponges Halichondria okadai and H. japonica exhibit a general decrease of their FAA content during hypo-osmotic stress, whereas FAA content appears to increase in the coral Acropora aspera under these conditions $[16,19,20]$. Several other environmental stressors, such as temperature and elevated $\mathrm{CO}_{2}$, cause changes in the expression of specific molecular chaperones in corals $[21,22]$ and these are likely to be components of a general stress response system.

While the literature on the molecular responses of corals to hypo-osmotic stress is very limited, comprehensive datasets are available for some other marine invertebrates [21, 22]. In mussels, for example, responses to hypo-osmotic stress include increases in levels of oxidative stress proteins and proteolysis, as well as changes in expression of membrane transporter proteins, although closely related species have been shown to respond differently [23]. In the present study, the transcriptomic response of the common reef-building coral Acropora millepora to hypo-saline conditions was investigated. Through the availability of a whole genome assembly and a comprehensive set of protein predictions for this organism, it is now possible to compare the response of this coral to those of other marine invertebrates, to tease apart specific and general responses to different environmental stressors [21, 24, 25]. Here we exposed adult colonies of Acropora millepora, as well as aposymbiotic juveniles (devoid of any photosynthetic symbionts), to hypo-saline conditions mimicking those experienced in extreme weather events (25 PSU for the adults and 28 PSU for the juveniles). Although changes in the microbiome have previously been reported [26], this is the first study to comprehensively describe the molecular response of a coral to hypo-saline stress, and identifies both specific and general components of the response of A. millepora to environmental stressors.

\section{Methods}

\section{Coral salinity stress experiment}

The work described here was carried out under GBRMPA permit G09/30327.1. Eight Acropora millepora colonies were collected from Orpheus Island, Queensland, Australia $\left(18^{\circ} 39^{\prime} 52.43^{\prime \prime} \mathrm{S}, 146^{\circ} 29^{\prime} 42.38^{\prime \prime} \mathrm{E}\right)$ in June 2013 and transferred to the Australian Institute of Marine Science's National Sea Simulator (SeaSim) facility where the colonies were acclimated for 14days in outdoor aquaria at $\sim 27^{\circ} \mathrm{C}$. Each colony was fragmented into 25 nubbins $(\sim 6 \mathrm{~cm})$ that were then randomly distributed across nine $50 \mathrm{~L}$ tanks. The tanks were linked to a computer-controlled flow-through system supplying $0.4 \mu \mathrm{m}$ filtered seawater (FSW) maintained at $25.7^{\circ} \mathrm{C}$ $\left( \pm 0.6^{\circ} \mathrm{C}\right)$ and an ambient salinity of 35 PSU. UV-filtered lights were mounted above each tank and nubbins were exposed to an intensity of $250 \mu \mathrm{E}$ over a 12:12 h light/dark cycle (type of lights: $400 \mathrm{~W}$ metal halide lamps, BLV). The nubbins were acclimated in this system for a further 19 days to allow recovery. At the beginning of the experiment, corals were transferred to two tanks (one per treatment), the flow was stopped to ensure no water exchange and tanks were oxygenated via a pump (Tunze 6015). The nubbins were subsequently exposed to one of two salinity regimes for the duration of the experiment (24h): ambient/control salinity of 35 PSU $(n=45)$, or low salinity of 25 PSU $(n=40)$. Some nubbins were used as test samples before the start of the experiment and to test the effects of treatments not included in this study, hence the larger number of nubbins at the beginning of the experiment. The 25 PSU FSW was prepared by diluting $700 \mathrm{ml}$ of 35 PSU FSW with $300 \mathrm{ml}$ reverse-osmosis water. The temperature during the treatment period was maintained at $25.9 \pm 0.7^{\circ}$ C. Salinity was monitored using a water quality meter (TPS 90FL, ThermoFisher). Coral nubbins ( $n=1$ per colony, for both control and treatment) were sampled at two time points for RNA analysis, at 1 and $24 \mathrm{~h}$ post the salinity change (samples were taken at 12:00 and 1:00 pm respectively). A total of 18 nubbins for RNA analysis $(n=5$ per time point for each condition, but $n=3$ in the case of the $24 \mathrm{~h}$ treatment) were snap frozen in liquid nitrogen and stored at $-80^{\circ} \mathrm{C}$.

\section{Juvenile coral salinity stress experiment}

For the experiment on coral juveniles, six Acropora millepora colonies were collected from Trunk Reef, GBR, Australia (18 $\left.22^{\prime} 15.10^{\prime \prime} \mathrm{S} / 146^{\circ} 48^{\prime} 27.82^{\prime \prime} \mathrm{E}\right)$ and transferred to the National Sea Simulator (SeaSim) facility prior to the predicted spawning event in November 2013. Colonies were individually placed in $70 \mathrm{~L}$ tanks with $0.2 \mu \mathrm{m}$ of filtered seawater (FSW). After spawning, gametes were collected and mixed to allow fertilization to occur. Fertilized embryos were transferred to larval rearing tanks and raised as described in Tebben et al. 
[27] and Raina et al. [28]. At 13 days post-fertilization, larvae were collected using a $1 \mathrm{~mm}$ mesh net, washed three times in $0.2 \mu \mathrm{m} \mathrm{FSW}$ and then settled in (sterile) 6-well plates (8 plates per species, 40 larvae per well; each well filled with $4 \mathrm{ml}$ of ambient salinity (35 PSU) $0.2-\mu \mathrm{m}$ FSW) using a cue $(5 \mu \mathrm{L})$ derived from crustose coralline algae (CCA; see Siboni [29]). Throughout the incubation phase, the plates were maintained in the dark at $26.3^{\circ} \mathrm{C}( \pm 0.01)$ and the FSW was changed every second day. Four days post-settlement (T0), plates were separated into two groups: 16 plates were maintained at 35 PSU (control salinity) while the seawater in the remaining 16 plates was exchanged for 28 PSU (salinity stress treatment). The salinity stress applied in the case of the juveniles (28 PSU) was slightly less challenging than that used for the adults (25 PSU) based on the high mortality rate observed at 25 PSU during a pilot study. Samples were collected for RNA after $24 \mathrm{~h}$ (T24), and $48 \mathrm{~h}$ (T48) at 2:00 pm each day $(n=23$ samples; $n=6$ wells per treatment per time point, but $n=5$ in the case of the $48 \mathrm{~h}$ control).

RNA extraction sequencing and gene expression analyses Total RNA was extracted from 18 adult nubbins of five genotypes of 25 and 35 PSU treatments $(n=5$ for each condition per time point, but $n=3$ for $24 \mathrm{~h}$ treatment) following the same methods described in Aguilar et al. [30]. Coral juveniles were sampled by removing the water and adding $1.5 \mathrm{~mL}$ of RNAlater (Ambion, cat\# AM7021) simultaneously to each well ( $n=40$ juveniles) and scraping the content with a sterile $200 \mu \mathrm{L}$ plastic tip to transfer the contents into a 2 $\mathrm{mL}$ tube and stored at $-20^{\circ} \mathrm{C}$. Twenty four samples ( $n=6$ wells per treatment per time point) from the content of each well were used to extract total RNA using the RNAaqueous-Micro total RNA isolation kit (AM1931, AMBION). The quality and quantity of RNA preparations were determined using a Bioanalyzer (Agilent 2100 Bioanalyzer) with samples prepared following the Agilent RNA 6000 Nano Kit instructions (cat \# 5067-1511).

RNAseq libraries (18 for the adults and 23 for the juveniles) were constructed using the NEB Next Ultra Directional RNA Library Prep Kit for Illumina (NEB, E7420S) following the manufacturers recommended protocol, and $100 \mathrm{bp}$ paired-end sequence data obtained using a HiSeq 2000 at the Biomolecular Resource Facility (Australian National University). After trimming (70-80\% of reads retained), reads were mapped onto the Acropora millepora genome (Ying et al., in prep) using TopHat2 [31] and counts data generated using htseq-count [32] for subsequent analysis. The mapping efficiency varied significantly, in general being much higher for larvae $(>80 \%)$ than for adults (45-60\%) due to the presence of Symbiodiniaceae in the latter. Approximately $70 \%$ of mapped reads were counted as genes. Genes IDs in this paper refer to the $A$. millepora protein predictions (e.g. 1.2.1.m1) that have been deposited in the Gene Expression Omnibus (GEO) under the reference number GSE96916.

The read count matrix was analysed in $\mathrm{R}$ ( $\mathrm{R}$ Core Team 2014) using the package arrayQualityMetrics [33] to check for outliers, and was transformed (variance stabilizing transformation (VST)) to be visualized using a principal component analysis (PCA). Although potential effects of pseudoreplication caused by using only one tank per condition could not be tested, note that this has also frequently also been the case in similar published gene expression studies [34, 35]. The DESeq2 package [36] was used to test for differential gene expression due to the effects of salinity, while controlling for the effect of the genotype in the case of the adult dataset (design $=\sim$ genotype + treatment). For the juvenile dataset, as each sample was a mixture of genotypes, genotype effects could not be considered (design $=\sim$ treatment). Default functions for estimating size factors, dispersion and negative binomial Wald Test were used in DESeq2. Log2 fold changes $(\log 2 \mathrm{FC})$ in gene expression levels were obtained in DESeq2 by comparing control (35 PSU) vs. salinity treatment of four different comparisons: (i) control vs. treatment at $1 \mathrm{~h}$ in the adults, (ii) control vs. treatment at $24 \mathrm{~h}$ in the adults, (iii) control vs. treatment at $24 \mathrm{~h}$ in the juveniles and, (iv) control vs. treatment at $48 \mathrm{~h}$ in the juveniles. False discovery rate (FDR) adjusted $p$ values were controlled at $5 \%$ for each gene according to the methods of Benjamini and Hochberg [37].

Statistically over-represented gene ontology (GO) categories were determined in BiNGO [38] in Cytoscape 3.1.1 [39] using the hypergeometric test and a FDR significance level of $<0.01$ on the set of genes that were differentially up- or down-regulated in each dataset. These GO categories were used to search specific pathways in the Kyoto Encyclopedia of Genes and Genomes (KEGG) by downloading pathway sequences (using Homo sapiens and Nematostella vectensis as references for the pathways: protein processing in endoplasmic reticulum, nve0414, hsa04141; proteasome, nve03050, hsa03050; peroxisome, nve04146, hsa04146; lysosome, nve04142, hsa04142; glycine, serine and threonine metabolism, nve00260, hsa00260; glutathione metabolism, nve00480, hsa00480; alanine, aspartate and glutamate metabolism, nve00250, hsa00250; ABC transporters, nve02010, hsa02010) and blasting these sequences against the A. millepora protein predictions. All results are based on similarity of the A. millepora protein predictions to a reference annotated protein (evalue cut-off $=1 \mathrm{e}^{-4}$ ). 


\section{Results}

\section{Differential gene expression analyses}

Between 5.5-10.2 million RNAseq reads were obtained from each adult coral sample, while 3.4-8.8 million reads were recovered from each juvenile coral sample. PCA of the count matrix of the 26,622 A. millepora gene predictions revealed that the colony (i.e. genotype) had a stronger effect on gene expression than the salinity treatment for the adult corals, while in the case of juveniles (where genotype effects could not be accounted for) variation was primarily explained by treatment (Additional file 1: Figure S1). After $1 \mathrm{~h}$ of salinity stress, 2657 genes were differentially expressed in adults (DEGs; FDR <0.05), increasing to 3713 after $24 \mathrm{~h}$ of exposure (Additional file 2: Figure S2). Whilst 3462 genes were differentially expressed in the juveniles after $24 \mathrm{~h}$ of salinity stress, this number decreased to 1485 after $48 \mathrm{~h}$ of stress (Additional file 2: Figure S2). At the $24 \mathrm{~h}$ time point, adults and juveniles shared $38 \%$ of up-regulated genes (total number: 1707; FDR <0.05) and $31 \%$ of down-regulated genes (total number: 1755; FDR < 0.05; see Additional file 3: Figure S3). Moreover, the overall response to salinity stress included 98 genes that were differentially expressed in both adults and juveniles at both time points, amongst which were several genes involved in amino acid metabolism discussed below (Fig. 1, Additional file 4: Table S1).

Eighty-four GO terms were over-represented in the adults after $1 \mathrm{~h}$ of salinity stress, while this number decreased to $13 \mathrm{GO}$ terms after $24 \mathrm{~h}$ (Additional file 4: Table S2). For the juveniles, 48 GO terms were over-represented after $24 \mathrm{~h}$ of salinity stress and this number decreased to $33 \mathrm{GO}$ terms after $48 \mathrm{~h}$. At both time points the GO term with the highest FDR was the 'small molecular metabolic process' (FDR 1.17E-12 and 5.24E-07 after 24 and $48 \mathrm{~h}$ ). GO analysis revealed several categories that were down-regulated after $1 \mathrm{~h}$ but up-regulated after $24 \mathrm{~h}$ in the adults: (i) protein homeostasis, including: endoplasmic reticulum (ER), ER lumen, proteasome complex, cell catabolism and oxidoreductase activity; and (ii) amino acid and nitrogen metabolism. Based on these results, we used the sequences from specific KEGG pathways to find homologues in the coral transcriptome and understand the responses of these genes to hypo-saline stress.

\section{Proteolysis within the ER under hypo-saline conditions}

There was an up-regulation of several genes involved in ER-associated degradation (ERAD, ko04141) and the ubiquitin-proteasome system (UPS) after $24 \mathrm{~h}$ of hyposaline stress in the adults, while many of the same genes were down-regulated under acute $(1 \mathrm{~h})$ salinity stress (Fig. 2; Additional file 4: Table S3). The ER pathway involves several processes, including: protein folding and translocation into the ER lumen, degradation of misfolded proteins through the ERAD system and proteolysis through the UPS. Amongst the genes up-regulated after $24 \mathrm{~h}$ were coral homologues of genes responsible for translocation into the ER lumen; the oligosaccharyl transferase (OST) and SEC61 protein transport systems. Genes involved in protein glycosylation also showed increased expression after $24 \mathrm{~h}$; for example, glucosidase II (GlcII) increased by $0.66 \log _{2} \mathrm{FC}$ (FDR 8.95E-06, Additional file 4: Table S3), and UDP-glucose/glycoprotein glucosyltransferase (UGGT) increased by $0.59 \log _{2} \mathrm{FC}$ (FDR 8.82E-04). Moreover, luminal chaperones and cochaperones were also up-regulated at $24 \mathrm{~h}$, including the HSP70 family member GRP70, also known as binding immunoglobulin protein (BiP; 1.2.4351.m1; $1.3 \log _{2}$ FC; FDR 8.64E-19 at 24h), along with the BiP co-chaperones ERdj1, ERdj3 and ERdj6 (DnaJ Hsp40 family members; 1.2.7940.m1, 1.2.25530.m1, 1.2.21656.m1). Increased expression was also observed for members of the ERAD retrotranslocon complexes, including the endoplasmic reticulum lectin 1 (XTP3B, 1.2.21359.m1), heat shock protein $90 \mathrm{kDa}$ (GRP94, 1.2.15211.m1), translocating chainassociated membrane protein (TRAM, 1.2.11248.m1), and the translocon-associated protein (TRAP, 1.2.3165.m1).

Increased expression of components of the unfolded protein response (UPR) system was recorded after 1 and $24 \mathrm{~h}$ of hypo-saline stress (Fig. 2; Additional file 4: Table S3). The UPR system relies on three major transmembrane proteins involved in sensing stress that were differentially regulated during this experiment. Coral genes homologous to the serine/threonine-protein kinase/endoribonuclease IRE1 (IRE1), and its interacting pro-apoptotic effector BAX, were up-regulated after $1 \mathrm{~h}$ (0.30 $\log _{2} \mathrm{FC}$, FDR 2.59E-02 and $0.41 \log _{2} \mathrm{FC}$, FDR 2.78E-02 respectively; Fig. 2; Additional file 4: Table S3). In addition, genes homologous to the eukaryotic translation initiation factor 2-alpha kinase (PERK), and the activating transcription factor 6 (ATF6) were upregulated after $24 \mathrm{~h}$ of stress $\left(0.60 \log _{2} \mathrm{FC}, \mathrm{FDR}\right.$ 6.25E-03 and $0.42 \log _{2}$ FC, FDR $1.89 \mathrm{E}-02$ respectively; Fig. 2; Additional file 4: Table S3).

\section{The response of genes involved in oxidative stress and osmoregulation}

Genes involved in the peroxisomal antioxidant system that showed increased expression after $24 \mathrm{~h}$ of hypo-saline stress include: two superoxide dismutases (SOD, by 0.41 and $0.43 \log _{2}$ FC; FDR $1.07 \mathrm{E}-02$ and 4.68E-02), two catalases (CAT, by 0.49 and $1.44 \log _{2}$ FC; FDR $1.93 \mathrm{E}-31$ and 1.96E-02), and five glutathione S-transferases (GST, EC:2.5.1.18) (Additional file 4: Table S3, S4). The glutathione $(\mathrm{GSH})$ redox system also plays an important role in protection against oxidative damage. It comprises the enzymes glutathione peroxidase (GPx, EC 1.11.1.9) (oxidizing 


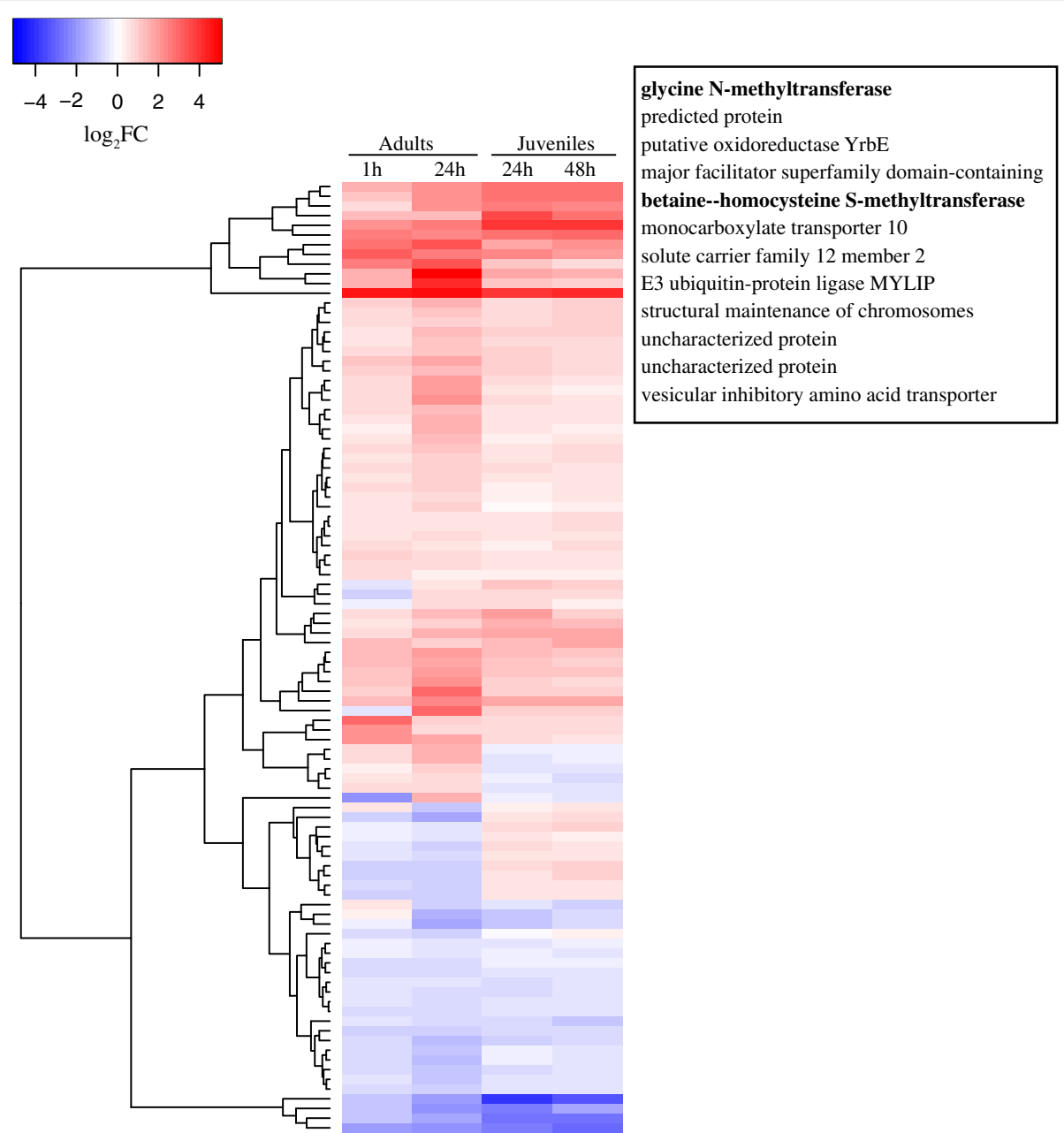

Fig. 1 Heatmap ( $\log _{2} F C$ ) summarising expression relative to 35 PSU controls of the suite of 98 genes which responded (FDR $\left.<0.05\right)$ in all four salinity treatments. As indicated above the corresponding columns in the heatmap, the treatments were: $1 \mathrm{~h}$ (25 PSU) adults; $24 \mathrm{~h}$ ( 25 PSU) adults; $1 \mathrm{~h}$ (28 PSU) juveniles; $48 \mathrm{~h}$ (28 PSU) juveniles. The dendrogram on the left of the figure shows clustering based on similarity of expression pattern. To the right of the figure, the 12 most highly up-regulated genes are listed, those in bold being components of the free amino acid cycle (Additional file 4: Table S5). These 12 genes constitute a well resolved clade at the top of the heat map. For the complete list of genes IDs refer to Additional file 4: Table S1. The colour scale bar indicates up (red) or down-regulation (blue) relative to the control

GSH to glutathione disulphide (GSSG)), and glutathione reductase (GSR) (reducing GSSG back to glutathione). During hypo-saline stress, the GSR homologue was upregulated after $24 \mathrm{~h}$, while the GPx homologue was down-regulated after 1 and $24 \mathrm{~h}$ of stress by -0.38 and $1.08 \log _{2}$ FC respectively (FDR $1.30 \mathrm{E}-03$ and 7.61E-10; Fig. 3; Additional file 4: Table S5), indicating a balance towards GSH reduction.

Osmotic stress involves changes in the cellular concentrations of many inorganic and organic molecules, and this was corroborated by altered expression of many genes associated with transport of ions or organic molecules, including several solute carrier (SLC) families, ATPases, voltage-gated $\mathrm{K}^{+}$channels, and voltage-dependant $\mathrm{Ca}^{2+}$ channels (VDCC). After $1 \mathrm{~h}$ of salinity stress, three of the nine $\mathrm{Na}^{+} /\left(\mathrm{Ca}^{2+}-\mathrm{K}^{+}\right)$exchangers (SLC24) identified were up-regulated, while four $\mathrm{Na}^{+}$and $\mathrm{Cl}^{-}$dependent transporters (SLC6) were down-regulated (Additional file 4: Table S6). After 24h, eight SLC6 genes and three SLC24 genes were down-regulated. In the case of ATPases, five genes were down-regulated after $1 \mathrm{~h}$, whereas five were up-regulated after $24 \mathrm{~h}$ of stress. Amongst the ATPases, the relative expression of the sarco/endoplasmic reticulum $\mathrm{Ca}^{2+}$ ATPase (SERCA; an ER-associated $\mathrm{Ca}^{2+}$ influx channel) changed from $-1.40 \log _{2} \mathrm{FC}$ at $1 \mathrm{~h}$ to $1.63 \log _{2} \mathrm{FC}$ after $24 \mathrm{~h}$ (FDR 1.15E-09 and 3.59E-05 respectively). Conversely, expression of inositol 1,4,5-trisphosphate receptors (IP3Rs), which are $\mathrm{Ca}^{2+}$ efflux channel components, was down-regulated after $24 \mathrm{~h}$ (FDR $-1.35 \quad \log _{2} \mathrm{FC}$; 4.05E-03; Fig. 2; Additional file 4: Table S3). In addition, three voltage-dependant $\mathrm{Ca}^{2+}$ channels were not differentially expressed after $1 \mathrm{~h}$, but down-regulated after $24 \mathrm{~h}$. 

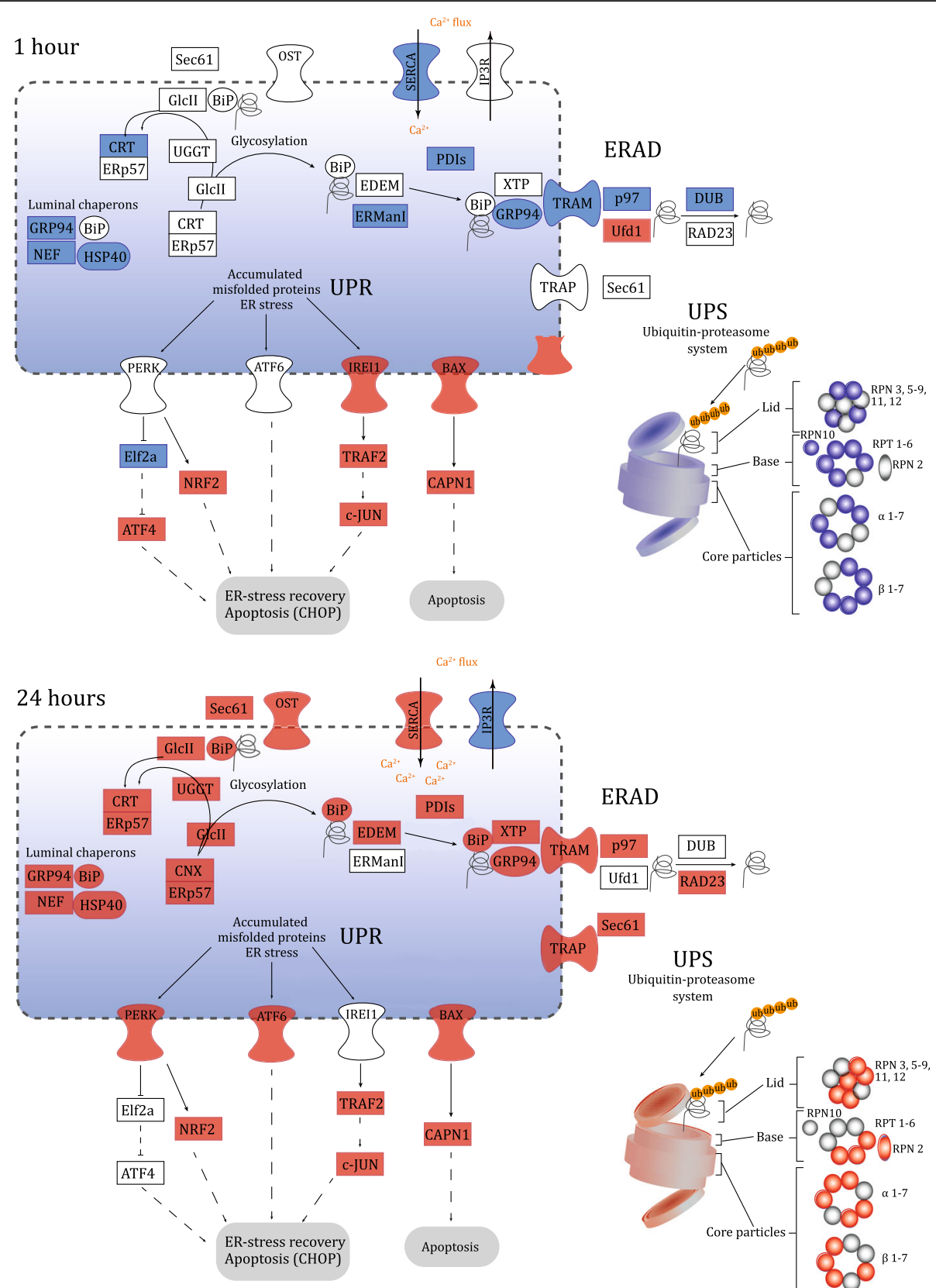

Fig. 2 Differential expression of A. millepora homologues of components of the ER protein processing machinery (pathway 04141) after exposure of adult corals to 1 and $24 \mathrm{~h}$ of hypo-saline conditions. Colours represent genes (FDR $<0.05$ ) that are up (red) or down-regulated (blue). The systems involved in ER protein processing and ER stress are indicated: glycosylation, ER associated degradation (ERAD), ubiquitin-proteasome system (UPS), and the unfolded protein response (UPR). A complete list of the genes involved in this pathway and log $\mathrm{F}_{2} \mathrm{FC}$ values is provided as Additional file 4: Table S3. Figure adapted from KEGG pathway database

\section{Glycine betaine and glutamate catabolism under hypo- saline stress}

$\mathrm{GO}$ analysis revealed an over-representation of terms associated with amino acid metabolism, with a strong response of genes implicated in glycine betaine catabolism following osmotic stress in the adults (Fig. 3; Additional file 4: Table S5). The first step in glycine betaine catabolism involves betaine-homocysteine $S$-methyltransferase
(BHMT), which transfers a methyl group from glycine betaine to homocysteine to produce dimethylglycine (DMG) and methionine. In the work described here, two betaine-homocysteine $S$-methyltransferase (BHMT) homologues were up-regulated (by 2.5 and $5.43 \log 2 \mathrm{FC}$; FDR $6.39 \mathrm{E}-70$ and $2.38 \mathrm{E}-69)$ after $24 \mathrm{~h}$ of stress. The DMG produced by the BHMT reaction can be converted to glycine by two enzymes (DMGDH and SARDH, Fig. 3), 


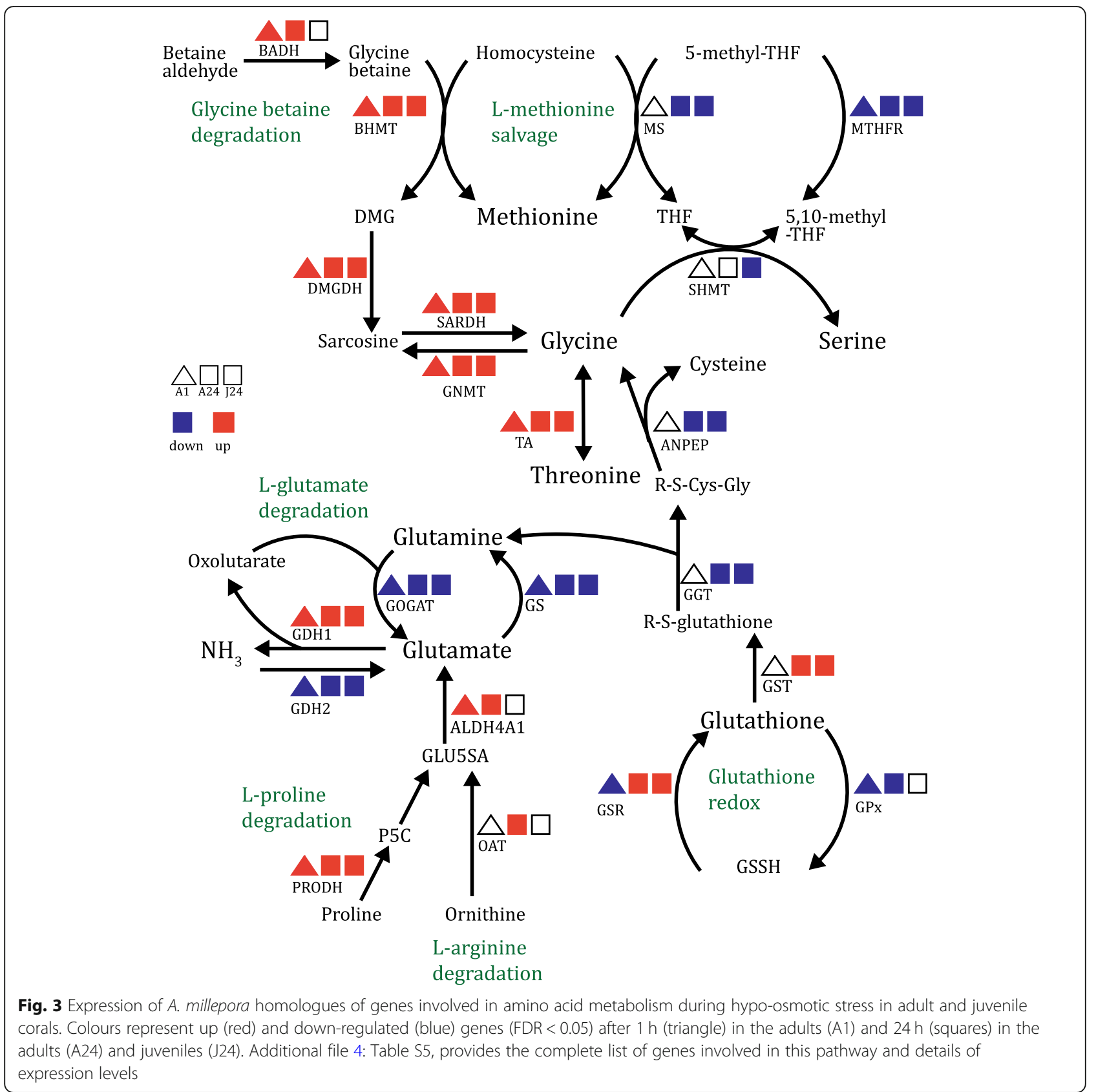

homologues of both of which were up-regulated after 1 and $24 \mathrm{~h}$ of hypo-saline stress.

Hypo-saline stress also caused changes in the expression of genes involved in ammonia assimilation. The coral NADH-dependant glutamate dehydrogenase (GDH1), which catalyses the release of ammonia from glutamate, was up-regulated after 1 and $24 \mathrm{~h}$ of stress $\left(\log _{2} \mathrm{FC}\right.$ of 0.47 and 2.54 respectively; FDR $1.21 \mathrm{E}-02$ and $4.28 \mathrm{E}-55)$. Conversely, genes involved in ammonia assimilation - the NADPH-dependant GDH (GDH2), glutamine synthase (GS), and glutamate synthase (GOGAT) - were down-regulated (Fig. 3; Additional file 4: Table S5). Genes involved in the L-arginine degradation pathway were also up-regulated in hypo osmotic stress, expression of both ornithine transaminase (OAT), and pyrroline-5-carboxylate dehydrogenase (ALDH4A1) increasing (by 0.52 and 1.51 $\log _{2} \mathrm{FC}$ respectively; FDR $2.16 \mathrm{E}-05$ and $1.10 \mathrm{E}-11$ ) after $24 \mathrm{~h}$ (Fig. 3; Additional file 4: Table S5).

The responses of coral juveniles to hypo-saline stress The responses of adult and juvenile corals were similar after $24 \mathrm{~h}$ of stress for a substantial number of DEGs (1191) (Additional file 3: Figure S3). For example, genes encoding proteasome subunits, components of the UPR 
system, and glycine betaine catabolism were up-regulated in both juveniles and adults after $24 \mathrm{~h}$ (see above). Conversely, three important ER luminal chaperones (BiP, GRP94 and NEF) showed opposite expression trends in the two life stages, being up-regulated in adults but down-regulated in juveniles (Additional file 4: Table S3). Of the four treatments studied, the prolonged $(48 \mathrm{~h})$ exposure of juveniles resulted in the lowest number (1485, FDR $<0.05$ ) of differentially expressed genes in response to hypo-saline conditions. After $48 \mathrm{~h}$, expression levels of many genes that were differentially expressed after $24 \mathrm{~h}$ in juveniles had returned to control levels, suggesting that a degree of acclimation may have occurred. For example, only two ubiquitin-proteasome system (UPS) subunits were differentially expressed at $48 \mathrm{~h}$, whereas ten were so at $24 \mathrm{~h}$ (Additional file 4: Table S3). A similar decrease was observed in the case of E2 ubiquitin-conjugation enzymes - from 13 to three up-regulated members after 24 and $48 \mathrm{~h}$ respectively (Additional file 4: Table S3).

\section{Discussion}

Gene expression data revealed a strong response of the coral A. millepora to hypo-saline stress, with clear differences between acute salinity shock $(1 \mathrm{~h})$ and more prolonged $(24 \mathrm{~h})$ exposure in adult corals. Here we describe a group of genes that are part of a general response to stress in corals, and a second group that are known to respond to osmotic stress in other organisms but were not previously described in corals. The first group includes genes involved in antioxidant production, and in protein homeostasis (comprising molecular chaperones, components of the ER associated protein degradation (ERAD) and unfolded protein response (UPR) systems). The second group comprises genes involved in osmoregulation, including molecular transporters and amino acid metabolism, particularly glycine betaine. Together, variations in the expression of these two groups of genes provide insights into the molecular basis of hypo-osmotic stress in corals and the changes involved in adjusting to this stress over time.

\section{The common response to stress in corals}

Hypo-saline stress induces expression of antioxidant defences that are protective against the reactive oxygen species (ROS) that arise in corals (and other organisms) as a result of a range of environmental stressors [40]. In the present study components of the general antioxidant repertoire of corals (catalases, superoxide dismutases and thioredoxin) that respond to thermal and to elevated $\mathrm{CO}_{2}$ stress $[14,24,25,41]$ were also found to respond to hypo-saline stress (Table 1). A second group of genes involved in general stress responses is the HSP family. For some time, HSPs have been investigated in the context of responses of corals to thermal stress [42-44], but the
HSP repertoire has only recently been properly described in A. millepora, allowing comprehensive analyses of the response of this complex gene family to stress [24]. Whereas multiple HSP90 and HSP70 variants are present in corals, some of which can respond to a range of stressors [14, 25, 42, 45], specific HSPs appear to respond to most types of stress. For example, Moya et al. $[24,46]$ identified a specific A. millepora HSP70 that also responded to high $\mathrm{CO}_{2}$ and whose $A$. hyacinthus orthologue was involved in thermal tolerance [47]. Consistent with a role in the general stress response, this same HSP70 responded to hypo-saline conditions in the present study (1.2.19257.m1, 2.54 $\log _{2}$ FC; FDR 3.42E-10 at $24 \mathrm{~h}$, Table 1 ).

Of the HSPs associated with ER processes, the luminal chaperone GRP94 (Fig. 2, Additional file 4: Table S3, 1.2.15211.m1) is of particular interest. As in other systems, this calcium-binding protein blocks apoptosis, and plays a key role in facilitating recovery from ER stress [48]. GRP94 expression was elevated after $24 \mathrm{~h}$ of salinity stress, and also responded to acute $\mathrm{CO}_{2}[24]$ and thermal stress in corals [43]. The mussel (Mytilus galloprovincialis) orthologue also responded to hypo-saline stress [49] (Table 1). In the present study, the ER-lumenal HSP70 BiP, which is involved in protein folding and is a component of the ERAD system [50] was up-regulated under hypo-saline conditions, and is also induced by challenge with bacteria [51] or lipopolysaccharide (LPS [52];). However, BiP was not differentially expressed under high $\mathrm{CO}_{2}$ stress [24], suggesting that it has a broad, but not universal, role in coral stress responses (Table 1).

Down-regulation of ERAD system components was observed after the acute salinity treatment $(1 \mathrm{~h})$; however unfolded protein response (UPR) system components were up-regulated after both 1 and $24 \mathrm{~h}$, suggesting that misfolded proteins accumulated as early as $1 \mathrm{~h}$ after the onset of osmotic stress. The activation of the UPR system can have two opposite outcomes: it can promote survival and resistance to ER stress and/or it can activate a cell death response [53]. For example, in mammals the endoribonuclease inositol-requiring enzyme-1 (IRE1) signalling protein can interact with the pro-apoptotic protein BAX, or it can activate c-JUN to promote cell survival [53]. Like its mammalian orthologue, coral BAX promotes cell death [54], but up-regulation of BAX under hypo-osmotic stress was small compared to that of the pro-survival protein, c-JUN, suggesting that the latter outcome might predominate during hypo-saline stress. Previous studies by Maor-Landaw et al. [55] in Stylophora pistillata found that PERK increased during temperature stress, and expression of c-JUN and MAPK7 homologues increased under hypo-saline stress in mussel [21]. There is also evidence of a general 
Table 1 Comparison between genes that are differentially expressed in A. millepora adults under hyposaline conditions and other published gene expression or proteomic studies

\begin{tabular}{|c|c|c|c|c|c|c|c|c|}
\hline Gene & Species & $\begin{array}{l}\text { Type of } \\
\text { treatment }\end{array}$ & Life stage & $\begin{array}{l}\text { Direction of } \\
\text { expression or } \\
\text { concentration }\end{array}$ & Time point & Type of data & Authors & Sequence ID \\
\hline \multicolumn{9}{|c|}{ Oxidative stress } \\
\hline \multirow{4}{*}{ Catalase } & A. millepora & Hypo-saline & Adults & $\uparrow$ & $24 \mathrm{~h}$ & RNAseq & This study & 1.2.6992.m1, 1.2.12339.m1 \\
\hline & A. millepora & $\mathrm{High} \mathrm{CO}_{2}$ & Juveniles & $\uparrow$ & 9 days & RNAseq & Moya et al. (2015) & Cluster008875 \\
\hline & S. pistillata & Hypo-saline & Adults & $\uparrow$ & $24 \mathrm{~h}$ & Immunoessay & Downs et al. (2009) & - \\
\hline & A. hyacinthus & High temperature & Adults & $\uparrow$ & $72 \mathrm{~h}$ & RNAseq & Barshis et al. (2013) & contig177311_209973 \\
\hline \multirow{4}{*}{$\mathrm{Cu} / \mathrm{Zn} \mathrm{SOD}$} & A. millepora & Hypo-saline & Adults & $\uparrow$ & $24 \mathrm{~h}$ & RNAseq & This study & $1.2 .240 . \mathrm{m} 1,1.2 .22720 . \mathrm{m} 1$ \\
\hline & S. pistillata & Hypo-saline & Adults & $\uparrow$ & $24 \mathrm{~h}$ & Immunoessay & Downs et al. (2009) & - \\
\hline & M. galloprovincialis & Hypo-saline & Adults & $\uparrow$ & $4 \mathrm{~h}$ & Proteomics & Tomanek at al. (2012) & gi|154349389 \\
\hline & M. trossulus & Hypo-saline & Adults & $\downarrow$ & $4 \mathrm{~h}$ & Proteomics & Tomanek at al. (2012) & gi|154349389 \\
\hline \multirow{4}{*}{ Thioredoxin } & A. millepora & Hypo-saline & Adults & $\uparrow$ & $24 \mathrm{~h}$ & RNAseq & This study & 1.2.61.m1 \\
\hline & M. galloprovincialis & Hypo-saline & Adults & $\uparrow$ & $4 \mathrm{~h}$ & Proteomics & Tomanek at al. (2012) & gi|238645469 \\
\hline & $\begin{array}{l}\text { Stylophora pistillata, } \\
\text { Acropora eurystoma, } \\
\text { Porites sp. }\end{array}$ & Heat-stress & Adults & $\uparrow$ & $5,10,13$ days & qPCR & $\begin{array}{l}\text { Maor-Landaw and Levy } \\
(2016)\end{array}$ & KT957160.1 \\
\hline & A. millepora & LED-light & Larvae & $\uparrow$ & $4 \mathrm{~h}$ & RNAseq & Strader et al. (2016) & - \\
\hline \multirow{2}{*}{$\begin{array}{l}\text { Thioredoxin } \\
\text { reductase }\end{array}$} & A. millepora & Hypo-saline & Adults & $\uparrow$ & $24 \mathrm{~h}$ & RNAseq & This study & 1.2.3068.m1 \\
\hline & M. galloprovincialis & Hypo-saline & Adults & $\uparrow$ & $4 \mathrm{~h}$ & Microarray & Lockwood at al. (2011) & gi|149381387 \\
\hline \multicolumn{9}{|c|}{ Protein chaperones } \\
\hline \multirow{5}{*}{ GRP94 } & A. millepora & Hypo-saline & Adults & $\uparrow$ & $24 \mathrm{~h}$ & RNAseq & This study & 1.2.15211.m1 \\
\hline & A. millepora & $\mathrm{High} \mathrm{CO}_{2}$ & Juveniles & $\uparrow$ & 3 days & RNAseq & Moya et al. (2015) & $\begin{array}{l}\text { Cluster010802 } \\
\text { Cluster005735 }\end{array}$ \\
\hline & A. millepora & High temperature & Larvae & $\uparrow$ & $3 \mathrm{~h}$ & qPCR & Rodriguez-Lanetty (2009) & - \\
\hline & S. pistillata & High temperature & Adults & $\uparrow$ & 5,10 , and $13 \mathrm{~d}$ & Microarray & Maor-Landaw et al. (2014) & CUST_5334_PI426075174 \\
\hline & M. galloprovincialis & Hypo-saline & Adults & $\uparrow$ & $4 \mathrm{~h}$ & Proteomics & Tomanek at al. (2012) & gi|238639046 \\
\hline \multirow{4}{*}{$\mathrm{BiP}$} & A. millepora & Hypo-saline & Adults & $\uparrow$ & $24 \mathrm{~h}$ & RNAseq & This study & $1.2 .4351 . \mathrm{m} 1$ \\
\hline & A. millepora & High temperature & Larvae & $\uparrow$ & $3 \mathrm{~h}$ & $\mathrm{qPCR}$ & Rodriguez-Lanetty (2009) & - \\
\hline & A. millepora & Bacteria challenge & Adults & $\uparrow$ & $24 \mathrm{~h}$ & qPCR & Brown et al. (2013) & - \\
\hline & A. millepora & LPS-challenge & Adults & $\uparrow$ & 1 and $24 \mathrm{~h}$ & RNAseq & Aguilar 2016 & $1.2 .4351 . \mathrm{m} 1$ \\
\hline \multirow{2}{*}{ ERdj6 } & A. millepora & Hypo-saline & Adults & $\uparrow$ & $24 \mathrm{~h}$ & RNAseq & This study & $1.2 .21656 . \mathrm{m} 1$ \\
\hline & S. pistillata & High temperature & Adults & $\uparrow$ & 5,10 , and $13 \mathrm{~d}$ & Microarray & Maor-Landaw et al. (2014) & CUST_8833_PI426075174 \\
\hline \multirow{3}{*}{ HSP70 } & A. millepora & Hypo-saline & Adults & $\uparrow$ & 1 and $24 \mathrm{~h}$ & RNAseq & This study & 1.2.19257.m1 \\
\hline & A. millepora & $\mathrm{High} \mathrm{CO}_{2}$ & Juveniles & $\uparrow$ & 3 and $9 \mathrm{~d}$ & RNAseq & Moya et al. (2015) & $\begin{array}{l}\text { Cluster007731, } \\
\text { Cluster005163 }\end{array}$ \\
\hline & A. hyacinthus & High temperature & Adults & $\uparrow$ & $72 \mathrm{~h}$ & RNAseq & Barshis et al. (2013) & contig187275 \\
\hline \multicolumn{9}{|c|}{ Osmotic stress signalling } \\
\hline \multirow{2}{*}{ c-JUN } & A. millepora & Hypo-saline & Adults & $\uparrow$ & 1 and $24 \mathrm{~h}$ & RNAseq & This study & $1.2 .21516 . \mathrm{m} 1$ \\
\hline & M. galloprovincialis & Hypo-saline & Adults & $\downarrow$ & $4 \mathrm{~h}$ & Microarray & Lockwood at al. (2011) & gi|145892475 \\
\hline \multirow{2}{*}{ MAPK7 } & A. millepora & Hypo-saline & Adults & $\uparrow$ & $1 \mathrm{~h}$ & RNAseq & This study & $1.2 .795 . \mathrm{m} 1$ \\
\hline & M. galloprovincialis & Hypo-saline & Adults & $\uparrow$ & $4 \mathrm{~h}$ & Microarray & Lockwood at al. (2011) & gi|145887901 \\
\hline \multicolumn{9}{|l|}{ Transporters } \\
\hline \multirow{2}{*}{ MCT } & A. millepora & Hypo-saline & Adults & $\downarrow$ & 24 & RNAseq & This study & 1.2.16615.m1 \\
\hline & M. galloprovincialis & Hypo-saline & Adults & $\downarrow$ & $4 \mathrm{~h}$ & Microarray & Lockwood at al. (2011) & gi|149383394 \\
\hline \multirow{2}{*}{ NACRA5 } & A. millepora & Hypo-saline & Adults & $\downarrow$ & $24 \mathrm{~h}$ & RNAseq & This study & 1.2.13318.m1 \\
\hline & M. galloprovincialis & Hypo-saline & Adults & $\downarrow$ & $4 \mathrm{~h}$ & Microarray & Lockwood at al. (2011) & gi|145890050 \\
\hline \multirow{2}{*}{ ATP1A1 } & A. millepora & Hypo-saline & Adults & $\downarrow$ & 1 and $24 \mathrm{~h}$ & RNAseq & This study & $1.2 .17116 . \mathrm{m} 1$ \\
\hline & M. galloprovincialis & Hypo-saline & Adults & $\downarrow$ & $4 \mathrm{~h}$ & Microarray & Lockwood at al. (2011) & gi|145882432 \\
\hline \multirow{2}{*}{ SLC6A5 } & A. millepora & Hypo-saline & Adults & $\uparrow$ & 1 and $24 \mathrm{~h}$ & RNAseq & This study & $1.2 .764 . \mathrm{m} 1$ \\
\hline & M. galloprovincialis & Hypo-saline & Adults & $\downarrow$ & $4 \mathrm{~h}$ & Microarray & Lockwood at al. (2011) & gi|145901661 \\
\hline \multirow{2}{*}{ SLC17A5 } & A. millepora & Hypo-saline & Adults & $\uparrow$ & $24 \mathrm{~h}$ & RNAseq & This study & $1.2 .312 . \mathrm{m} 1$ \\
\hline & M. galloprovincialis & Hypo-saline & Adults & $\downarrow$ & $4 \mathrm{~h}$ & Microarray & Lockwood at al. (2011) & gi|145883711 \\
\hline \multirow{2}{*}{ KCNA } & A. millepora & Hypo-saline & Adults & $\Downarrow$ & 1 and $24 \mathrm{~h}$ & RNAseq & This study & $1.2 .8080 . \mathrm{m} 1,1.2 .5849 . \mathrm{m} 1$ \\
\hline & M. galloprovincialis & Hypo-saline & Adults & $\uparrow$ & $4 \mathrm{~h}$ & Microarray & Lockwood at al. (2011) & gi|145882999 \\
\hline
\end{tabular}


increase of UPR associated genes in an expression module of the coral Acropora hyacinthus under high heat stress [56]. However, the present study is the first to document differential expression of the three main transmembrane proteins that regulate the UPR (BAX, IRE1, and PERK), and components of the corresponding downstream signalling pathways (Fig. 2; Additional file 4: Table S3).

\section{The specific response to hypo-saline stress in coral -Osmoregulation and transporters}

As adjustments to hypo-saline conditions require cell volume regulation, transport of ions through membranes plays an important role in adjusting this osmotic potential, and is mediated by $\mathrm{H}^{+}$translocating ATPases, $\mathrm{Ca}^{2}$ ${ }^{+}$-ATPases, secondary active transporters, and channels [57]. While ion transport proteins have been extensively characterized in higher animals, fungi and plants [58, 59], little is known about these genes families in cnidarians (but see $[60,61]$ ). When the results of the present study were compared with those derived from mussels under hypo-saline stress, the expression of several specific transporters (MCT, Nacra5, and ATP1A1) showed similar trends, whereas an opposite response was observed for others (SLC6A5, SLC17A5, and KCNA, Table 1). However, some of these apparent differences may be a consequence of the difficulty in identifying true orthologues across the deep evolutionary divide between molluscs and cnidarians (Table 1 and Additional file 4: Table S7). In general, and as mentioned by Lockwood and Somero [21], the responses of these transporters reflect two opposite adaptive mechanisms to stress: (i) moving ions across the membrane to stop cell swelling, and (ii) arresting the transport activities when solute concentrations inside the cell exceed requirements [62, 63]. Some of the results presented here might reflect these opposing activities, but also highlight the complexity of the gene families involved.

Marine invertebrates adjust their osmotic concentration not only by inorganic ion fluxes, but also via organic osmolytes such as taurine or betaines. Glycine betaine is thought to be an important osmolyte in corals, constituting $>90 \%$ of the organic solutes measured in Fungia, Pocillopora, Montipora and Tubastrea [18, 64]. Increased transcription of genes involved in glycine betaine catabolism was observed in the present study, implying that degradation of this compound occurred during hypo-osmotic stress (Fig. 3, Additional file 4: Table S5). Previous experiments on the effects of hypo-saline stress in the Pacific oyster Crassostrea gigas also found an increase in transcription of betaine-homocysteine S-methyltransferase (BHMT), a key enzyme of glycine betaine catabolism [65]. Glycine betaine concentrations decrease under hypo-saline stress in the marine alga
Platymonas subcordiformis [66], consistent with this compound acting as an osmoticum. Interestingly, the concentration of the organic sulfur compound dimethylsulfoniopropionate (DMSP), a well-known osmolyte in plants which increases in corals under heat stress [28], also increased under hypo-saline conditions during our study [30], suggesting that DMSP is unlikely to act as an osmolyte in corals, but rather as a scavenger of ROS and molecular sink for excess methionine.

In a range of marine invertebrates, including the sea anemone Metridium senile and the bivalve Noetia ponderosa $[15,16]$, free amino acid (FAA) levels also decrease in response to hypo-osmotic stress. However, the limited body of work on FAA metabolism in corals is not consistent with this trend (as it was found to increase in the coral $A$. aspera during hypo-saline stress [19]). The data presented here suggest that amino acid catabolism increased under hypo-saline stress, leading to increased ammonia production (GDH up-regulated, Fig. 3 ), but measurements of amino acid levels are needed to confirm osmolyte responses under hypo-saline stress.

\section{The response of adult coral vs. juveniles to hypo-saline stress}

Whereas previous work on salinity stress has focused on adult corals, this is the first investigation to consider both adult and juvenile corals. Since the juveniles were aposymbiotic, the response of juveniles documented here permits insights into molecular mechanisms operating in the coral animal in the absence of metabolic contributions [67] from endosymbiotic Symbiodiniaceae. Therefore, an important caveat in interpreting these results is that the presence/absence of endosymbiont in adults/juveniles. Despite this difference, after $24 \mathrm{~h}$ of osmotic stress, many aspects of the response were common between the adults and juveniles - for example, genes involved in adjusting cell volume (e.g., transporters, betaine catabolism). Several genes involved in amino acid metabolism also responded in the same way in both juveniles and adults (Fig. 3), and of particular interest was the increase of BHMT, an enzyme involved in methionine biosynthesis, at both time points, with a maximum change after $48 \mathrm{~h}$ in the juveniles (Additional file 4: Table S5; 4.04 $\log _{2} \mathrm{FC}$; FDR 0). This observation could be linked to increases in DMSP production observed with both life history stages during this experiment [30], since methionine is a precursor of DMSP. By contrast, the antioxidant system was up-regulated in adults and largely unaffected by hypo-osmotic stress in juveniles (Additional file 4: Table S4). This result could be explained as the adult corals have evolved mechanisms to withstand ROS produced by their endosymbionts [68]. 
In the case of juveniles, significantly fewer genes were differentially expressed after $48 \mathrm{~h}$ compared to $24 \mathrm{~h}$ of exposure to hypo-saline conditions, with the return to baseline levels of many of the genes implicated in proteolysis and osmoregulation suggesting a degree of acclimation had occurred after $48 \mathrm{~h}$. A precedent for this is provided by the work of Moya et al. [24] on the response of $A$. millepora juveniles to elevated $\mathrm{CO}_{2}$, where short term ( $3 \mathrm{~d}$ ) exposure to elevated $\mathrm{CO}_{2}$ caused changes in the expression of multiple genes, most of which returned to baseline levels after $9 \mathrm{~d}$ of exposure. Whilst these results suggest the possibility of acclimation to hypo-saline stress after $48 \mathrm{~h}$, experiments with longer exposure times are needed to understand if this response is maintained and how such treatments impact coral physiology.

\section{Conclusions}

During extreme floods, such as occurred on the GBR in 2010-2011, shallow reefs $(<5 \mathrm{~m})$ were exposed to salinity below 25 PSU for up to 15 days [12]. The frequency and severity of heavy rainfall events are predicted to increase by $2050[69,70]$, leading to corresponding increases in the exposure of adult and juvenile corals to hypo-saline conditions. The data presented here highlight specific pathways involved in the molecular response of corals to salinity stress, and imply that juvenile corals may have the ability to adjust to hypo-saline conditions during heavy rainfall events. However, longer term experiments, combined with physiological and proteomic analyses, should be a high priority.

\section{Additional files}

Additional file 1 Figure S1. Principal component analysis (PCA) from the normalized expression values of 26,622 genes in coral adults and juveniles. (a) Adults, each colour represents a colony (C1-C5, $n=4$ per colony). (b) Juveniles, each colour represents a salinity treatment $(n=11$ per treatment). PCA was generated from the variance stabilizing transformation (VST) values using "ggplot" in R [33]. (PDF $118 \mathrm{~kb}$ ). (PDF $239 \mathrm{~kb})$

Additional file $\mathbf{2}$ Figure S2. Total number of differentially expressed genes (DEGs) (FDR < 0.05) for each dataset. With the corresponding number of up-regulated (red) and down-regulated (blue) genes. (PDF 54 kb) (PNG $52 \mathrm{~kb}$ )

Additional file $\mathbf{3}$ Figure $\mathbf{S 3}$. Venn diagrams of the differentially expressed genes (FDR $<0.05)$ after $24 \mathrm{~h}$ hypo-saline stress that were up(red) and down- (blue) regulated in the adults and juveniles A. millepora corals. Indicating the subset of shared genes between each set of expression. (PDF $376 \mathrm{~kb}$ ) (JPG $367 \mathrm{~kb}$ )

Additional file 4 Table S1. Differentially expressed genes and their GO as in the heat map Fig. 1. Table S2. Gene enrichment analysis from $\mathrm{BiNGO}$ in Cytoscape 3.1.1. Each gene set identifies numbers of differentially expressed genes (FDR $<0.05$ ) in $\mathrm{GO}$ categories responding to salinity stress id adults or juveniles at the specified time points. Table S3. A. millepora homologues to the ER protein processing system. Results of the KEGG protein processing in the ER (nve04141) pathway searched in the A. millepora protein predictions. $\log _{2} \mathrm{FC}$ values of significantly expressed (FDR $<0.05)$ genes in response to the treatment (hypo-saline) over the control (35 PSU). Table S4. A. millepora homologues to the peroxisome and lysosome systems. $\log _{2} \mathrm{FC}$ are values of significantly expressed (FDR < 0.05) genes in response to the treatment (hypo-saline) over the control (35 PSU). Table S5 A. millepora homologues to amino acids metabolism. $\log _{2} \mathrm{FC}$ are values of significantly expressed (FDR $<$ 0.05 ) genes in response to the treatment (hypo-saline) over the control (35 PSU). Table S6. A. millepora homologues to membrane transporter. $\log _{2} F C$ are values of significantly expressed $(F D R<0.05)$ genes in response to the treatment (hypo-saline) over the control (35 PSU). Table S7. Comparison between differentially express (FDR $<0.05)$ genes in $A$. millepora under hypo-saline conditions and other published gene expression or proteomics data. (XLSX $130 \mathrm{~kb})$ (XLSX $118 \mathrm{~kb}$ )

\section{Abbreviations}

ANPEP: Aminopeptidase; BADH: Betaine-aldehyde dehydrogenase; BHMT: Betaine-homocysteine methyltransferase; DMGDH: Dimethylglycine dehydrogenase; GDH1: Glutamate dehydrogenase (NADH); GDH2: Glutamate dehydrogenase (NADPH); GGT: Gamma-glutamyltranspeptidase; GNMT: Glycine N-methyltransferase; GOGAT: Glutamate synthase; GPx: Glutathione peroxidase; GS: Glutamine synthetase; GSR: Glutathione reductase; GST: Glutathione S-transferase; MS: Methionine synthase; MTHFR: Methylenetetrahydrofolate reductase; OAT: Ornithine--oxo-acid transaminase; PRODH: Proline dehydrogenase; PSU: Practical salinity units; SARDH: Sarcosine dehydrogenase; SHMT: Serine hydroxymethyltransferase; TA: Threonine aldolase

\section{Acknowledgements}

The authors thank Victor Beltran and the staff of the National Sea Simulator (SeaSim) at the Australian Institute of Marine Science for their support, and Simon Davy (Victoria University, Wellington) for permission to cite results from an unpublished thesis. The authors also gratefully acknowledge Andrew Negri and Jan Tebben, for providing the coral larvae and extracts of crustose coralline algae, respectively, and assistance during the experiments. Finally, Sylvain Fôret was a major contributor to work reported here, and his untimely passing is not only a source of great sadness to many, but also represents a major loss to the marine genomics community.

\section{Funding}

CA gratefully acknowledges receipt of an AIMS@JCU scholarship, and the work was supported by the Australian Research Council via the ARC Centre of Excellence for Coral Reef Studies. Note that the funding bodies were not involved in the design of the study or in any aspect of the collection, analysis and interpretation of the data or paper writing.

\section{Availability of data and materials}

RNAseq reads were submitted to the Gene Expression Omnibus (GEO) under the reference number GSE96916. The Acropora millepora whole genome shotgun project has been deposited at DDBJ/ENA/GenBank under the accession PNJNA473876.

\section{Authors' contributions}

CA, DGB, DJM, and J-BR conceived and designed the experiments. CA, J-BR, $D C H, D G B$ and BL carried out the experiments. CA, J-BR, DCH and SF analysed the data. CA, J-BR, DGB and DJM wrote the manuscript, with input from all authors. All authors read the article and approved the final version.

Ethics approval and consent to participate

The work on corals described here was carried out under GBRMPA permit G09/30327.

\section{Consent for publication}

Not applicable.

\section{Competing interests}

The authors declare that they have no competing interests.

\section{Publisher's Note}

Springer Nature remains neutral with regard to jurisdictional claims in published maps and institutional affiliations. 


\section{Author details}

1AIMS@JCU and Department of Molecular and Cell Biology, James Cook University, Townsville, Queensland 4811, Australia. ${ }^{2}$ ARC Centre of Excellence for Coral Reef Studies and Department of Molecular and Cell Biology, James Cook University, Townsville, Queensland 4811, Australia. ${ }^{3}$ Cooperative Institute for Marine and Atmospheric Studies, Rosenstiel School of Marine \& Atmospheric Science, University of Miami, 4600 Rickenbacker Causeway, Miami, Florida 33149, USA. ${ }^{4}$ Atlantic Oceanographic and Meteorological Laboratories (AOML), NOAA, 4301 Rickenbacker Causeway, Miami, Florida 33149, USA. ${ }^{5}$ Climate Change Cluster (C3), University of Technology, Sydney, NSW 2007, Australia. ${ }^{6}$ Division of Ecology and Evolution, Research School of Biology, Australian National University, Canberra, ACT 2601, Australia. ${ }^{7}$ Laboratoire d'excellence CORAIL, Centre de Recherches Insulaires et Observatoire de l'Environnement (CRIOBE), MooreaB.P.1013, Papeete, French Polynesia. ${ }^{8}$ Australian Institute of Marine Science, Townsville, Queensland 4810, Australia. ${ }^{9}$ College of Science and Engineering, James Cook University, Townsville 4811, Australia.

\section{Received: 5 September 2018 Accepted: 13 February 2019}

Published online: 20 February 2019

\section{References}

1. Moberg F, Folke C. Ecological goods and services of coral reef ecosystems. Ecol Econ. 1999;29(2):215-33.

2. Bellwood DR, Hughes TP, Folke C, Nyström M. Confronting the coral reef crisis. Nature. 2004:429:827.

3. De'ath $G$, Fabricius KE, Sweatman H, Puotinen M. The 27-year decline of coral cover on the great barrier reef and its causes. PNAS. 2012;109(44): 17995-9.

4. Cantin NE, Cohen AL, Karnauskas KB, Tarrant AM, McCorkle DC. Ocean warming slows coral growth in the central red sea. Science. 2010;329(5989): 322.

5. Hughes TP, Barnes ML, Bellwood DR, Cinner JE, Cumming GS, Jackson JBC, et al. Coral reefs in the Anthropocene. Nature. 2017;546(7656):82-90.

6. Durack PJ, Wijffels SE, Matear RJ. Ocean salinities reveal strong global water cycle intensification during 1950 to 2000. Science. 2012;336:455-8.

7. Baker AC, Glynn PW, Riegl B. Climate change and coral reef bleaching: an ecological assessment of long-term impacts, recovery trends and future outlook. Estuar Coast Shelf Sci. 2008;80(4):435-71.

8. Xie S-P, Deser C, Vecchi GA, Ma J, Teng H, Wittenberg AT. Global warming pattern formation: sea surface temperature and rainfall*. J Clim. 2010;23(4): 966-86.

9. Van Woesik R, De Vantier LM, Glazebrook JS. Effects of cyclone 'Joy' on nearshore coral communities of the great barrier reef. Mar Ecol Prog Ser. 1995;128:261-70.

10. Devlin M, Taylor J, Brodie J. Flood plumes, extent, concentration and composition. GBRMPA Reef Res. 1998:8:1-9.

11. Butler IR, Sommer B, Zann M, Zhao JX, Pandolfi JM. The cumulative impacts of repeated heavy rainfall, flooding and altered water quality on the highlatitude coral reefs of Hervey Bay, Queensland, Australia. Mar Pollut Bull. 2015;96(1-2):356-67.

12. Berkelmans R, Jones AM, Schaffelke B. Salinity thresholds of Acropora spp. on the great barrier reef. Coral Reefs. 2012;31(4):1103-10.

13. Kerswell AP, Jones RJ. Effects of hypo-osmosis on the coral Stylophora pistillata nature and cause of 'low-salinity bleaching'. Mar Ecol Prog Ser. 2003;253:145-54.

14. Downs CA, Kramarsky-Winter E, Woodley CM, Downs A, Winters G, Loya Y, et al. Cellular pathology and histopathology of hypo-salinity exposure on the coral Stylophora pistillata. Sci Total Environ. 2009;407(17):4838-51.

15. Pierce SK, Warren JW. The taurine efflux portal used to regulate cell volume in response to hypoosmotic stress seems to be similar in many cell types: lessons to be learned from molluscan red blood cells. Amer Zool. 2001;41: 710-20.

16. Deaton LE, Hoffman RJ. Hypoosmotic volume regulation in the sea anemone Metridium senile. Comp Biochem Physiol. 1988;91(1):187-91.

17. Ochsenkühn MA, Röthig T, D'Angelo C, Wiedenmann J, Voolstra CR. The role of floridoside in osmoadaptation of coral-associated algal endosymbionts to high-salinity conditions. Sci Adv. 2017;3:e1602047.

18. Yancey Paul H, Heppenstall M, Ly S, Andrell Raymond M, Gates Ruth D, Carter Virginia L, et al. Betaines and dimethylsulfoniopropionate as major osmolytes in Cnidaria with endosymbiotic dinoflagellates. Physiol Biochem Zool. 2010;83(1):167-73.

19. Cowlin M. Osmoregulation and the anthozoan- dinoflagellate symbiosis: Victoria University of Wellington; 2012.

20. Shinagawa A, Suzuki T, Konosu S. The role of free amino acids and betaines in intracellular osmoregulation of marine sponges. NIPPON SUISAN GAKK. 1992;58(9):1717-22.

21. Lockwood BL, Somero GN. Transcriptomic responses to salinity stress in invasive and native blue mussels (genus Mytilus). Mol Ecol. 2011;20(3):517-29.

22. Tomanek L, Zuzow MJ. The proteomic response of the mussel congeners Mytilus galloprovincialis and M. Trossulus to acute heat stress: implications for thermal tolerance limits and metabolic costs of thermal stress. J Exp Biol. 2010;213(Pt 20):3559-74.

23. Lockwood BL, Sanders JG, Somero GN. Transcriptomic responses to heat stress in invasive and native blue mussels (genus Mytilus): molecular correlates of invasive success. J Exp Biol. 2010;213(Pt 20):3548-58.

24. Moya A, Huisman L, Foret S, Gattuso JP, Hayward DC, Ball EE, et al. Rapid acclimation of juvenile corals to $\mathrm{CO} 2$-mediated acidification by upregulation of heat shock protein and $\mathrm{BCl}-2$ genes. Mol Ecol. 2015; 24(2):438-52.

25. Barshis DJ, Ladner JT, Oliver TA, Seneca FO, Traylor-Knowles N, Palumbi SR. Genomic basis for coral resilience to climate change. PNAS. 2013;110(4): 1091-6490.

26. Röthig T, Ochsenkühn MA, Roik A, van der Merwe R, Voolstra CR. Long-term salinity tolerance is accompanied by major restructuring of the coral bacterial microbiome. Mol Ecol. 2016;25(6):1308-23.

27. Tebben J, Tapiolas DM, Motti CA, Abrego D, Negri AP, Blackall LL, et al. Induction of larval metamorphosis of the coral Acropora millepora by tetrabromopyrrole isolated from a Pseudoalteromonas bacterium. PLoS One. 2011;6(4):e19082.

28. Raina JB, Tapiolas DM, Foret S, Lutz A, Abrego D, Ceh J, et al. DMSP biosynthesis by an animal and its role in coral thermal stress response. Nature. 2013;502(7473):677-80.

29. Siboni N, Abrego D, Motti CA, Tebben J, Harder T. Gene expression patterns during the early stages of chemically induced larval metamorphosis and settlement of the coral Acropora millepora. PLoS One. 2014;9(3):e91082.

30. Aguilar C, Raina JB, Motti CA, Foret S, Hayward DC, Lapeyre B, et al. Transcriptomic analysis of the response of Acropora millepora to hypoosmotic stress provides insights into DMSP biosynthesis by corals. BMC Genomics. 2017;18(1):612.

31. Kim D, Pertea G, Trapnell C, Pimentel H, Kelley R, Salzberg SL. TopHat2: accurate alignment of transcriptomes in the presence of insertions, deletions and gene fusions. Genome Biol. 2013;14(4):R36.

32. Anders S, Pyl PT, Huber W. HTSeq--a Python framework to work with highthroughput sequencing data. Bioinformatics. 2015;31(2):166-9.

33. Kauffmann A, Gentleman R, Huber W. arrayQualityMetrics--a bioconductor package for quality assessment of microarray data. Bioinformatics. 2009; 25(3):415-6.

34. Kurman MD, Gómez CE, Georgian SE, Lunden JJ, Cordes EE. Intra-specific variation reveals potential for adaptation to ocean acidification in a coldwater coral from the Gulf of Mexico. Front Mar Sci. 2017;4:111.

35. González-Pech RA, Vargas S, Francis WR, Wörheide G. Transcriptomic resilience of the Montipora digitata Holobiont to low pH. Front Mar Sci. 2017;4:403.

36. Love MI, Huber W, Anders S. Moderated estimation of fold change and dispersion for RNA-seq data with DESeq2. Genome Biol. 2014;15(12):550.

37. Benjamini $Y$, Hochberg $Y$. Controlling the false discovery rate: a practical and powerful approach to multiple testing. J R Stat Soc, B. 1995;57(1):289-300

38. Maere S, Heymans K, Kuiper M. BiNGO: a Cytoscape plugin to assess overrepresentation of gene ontology categories in biological networks. Bioinformatics. 2005;21(16):3448-9.

39. Smoot ME, Ono K, Ruscheinski J, Wang PL, Ideker T. Cytoscape 2.8: new features for data integration and network visualization. Bioinformatics. 2011; 27(3):431-2.

40. Lesser MP. Oxidative stress in marine environments: biochemistry and physiological ecology. Annu Rev Physiol. 2006;68:253-78.

41. Maor-Landaw K, Levy O. Gene expression profiles during short-term heat stress; branching vs. massive Scleractinian corals of the Red Sea. PeerJ. 2016;4:e1814.

42. Leggat W, Seneca F, Wasmund K, Ukani L, Yellowlees D, Ainsworth TD. Differential responses of the coral host and their algal symbiont to thermal stress. PLoS One. 2011;6(10):e26687. 
43. Rodriguez Lanetty M, Harii S, Hoegh Gulberg O. Early molecular responses of coral larvae to hyperthermal stress. Mol Ecol. 2009;18(24):5101-14.

44. Seveso D, Montano S, Strona G, Orlandi I, Galli P, Vai M. The susceptibility of corals to thermal stress by analyzing Hsp60 expression. Mar Environ Res. 2014;99:69-75

45. Chow AM, Ferrier-Pages C, Khalouei S, Reynaud S, Brown IR. Increased light intensity induces heat shock protein Hsp60 in coral species. Cell Stress Chaperones. 2009;14(5):469-76.

46. Moya A, Huisman L, Ball EE, Hayward DC, Grasso LC, Chua CM, et al. Whole transcriptome analysis of the coral Acropora millepora reveals complex responses to $\mathrm{CO}_{2}$-driven acidification during the initiation of calcification. Mol Ecol. 2012;21(10):2440-54.

47. Traylor-Knowles N, Rose NH, Sheets EA, Palumbi SR. Early transcriptional responses during heat stress in the coral acropora hyacinthus. Biol Bull. 2017:232(2):91-100

48. Eletto D, Dersh D, Argon Y. GRP94 in ER quality control and stress responses. Semin Cell Dev Biol. 2010;21(5):479-85.

49. Tomanek L, Zuzow MJ, Hitt L, Serafini L, Valenzuela JJ. Proteomics of hyposaline stress in blue mussel congeners (genus Mytilus): implications for biogeographic range limits in response to climate change. J Exp Biol. 2012; 215(Pt 22):3905-16.

50. Araki K, Nagata K. Protein folding and quality control in the ER. Cold Spring Harb Perspect Biol. 2011;3(11):a007526.

51. Brown T, Bourne D, Rodriguez-Lanetty M. Transcriptional activation of c3 and hsp70 as part of the immune response of Acropora millepora to bacterial challenges. PLoS One. 2013;8(7):e67246.

52. Aguilar C. Transcriptomic analyses of the responses of corals to environmental stress. Townsville. Australia: James Cook University; 2016.

53. Darling NJ, Cook SJ. The role of MAPK signalling pathways in the response to endoplasmic reticulum stress. Biochim Biophys Acta. 2014;1843(10):2150-63.

54. Moya A, Sakamaki K, Mason BM, Huisman L, Forêt S, Weiss Y, et al. Functional conservation of the apoptotic machinery from coral to man: the diverse and complex $\mathrm{BCl}-2$ and caspase repertoires of Acropora millepora. BMC Genomics. 2016:17(1):62

55. Maor-Landaw K, Karako-Lampert S, Waldman Ben-Asher H, Goffredo S, Falini G, Dubinsky Z, et al. Gene expression profiles during short-term heat stress in the red sea coral Stylophora pistillata. Glob Chang Biol. 2014;20(10):3026-35.

56. Ruiz-Jones LJ, Palumbi SR. Tidal heat pulses on a reef trigger a fine-tuned transcriptional response in corals to maintain homeostasis. Sci Adv. 2017;3: e1601298.

57. Hasegawa PM, Bressan RA, Zhu J-K, Bohnert HJ. Plant cellular and molecular response to high salinity. Annu Rev Plant Physiol Plant Mol Biol. 2000:51:463-99.

58. Jan LY, Jan YN. Cloned potassium channels from eukaryotes and prokaryotes. Annu Rev Neurosci. 1997;20:91-123.

59. Wang $Y$, Wu WH. Potassium transport and signaling in higher plants. Annu Rev Plant Biol. 2013;64:451-76.

60. Zoccola D, Ganot P, Bertucci A, Caminiti-Segonds N, Techer N, Voolstra CR, et al. Bicarbonate transporters in corals point towards a key step in the evolution of cnidarian calcification. Sci Rep. 2015;5:9983.

61. Zoccola D, Tambutté E, Kulhanek E, Puverel S, Scimeca J-C, Allemand D, et al. Molecular cloning and localization of a PMCA P-type calcium ATPase from the coral Stylophora pistillata. BBA-Biomembranes. 2004;1663(1):117-26.

62. Pierce SK. Invertebrate cell volume control mechanisms: a coordinated use of intracellular amino acids and inorganic ions as osmotic solute. Biol Bull. 1982;163:405-19.

63. Hochachka PW, Somero GN. Biochemical adaptation : mechanism and process in physiological evolution. New York: Oxford University Press; 2002.

64. Hill RW, Armstrong EJ, Florn AM, Li C, Walquist RW, Edward A. Abundant betaines in giant clams (Tridacnidae) and western Pacific reef corals, including study of coral betaine acclimatization. Mar Ecol Prog Ser. 2017; 576:27-41

65. Zhang Y, Sun J, Mu H, Li J, Zhang Y, Xu F, et al. Proteomic basis of stress responses in the gills of the Pacific oyster Crassostrea gigas. J Proteome Res. 2015;14(1):304-17.

66. Dickson DMJ, Kirst GO. The role of beta-dimethylsulphoniopropionate glycine betaine and homarine in the osmoacclimation of Platymonas subcordiformis. Planta. 1986;167:536-43.

67. Davy SK, Allemand D, Weis VM. Cell biology of cnidarian-dinoflagellate symbiosis. Microbiol Mol Biol Rev. 2012;76(2):229-61.
68. Tchernov D, Gorbunov MY, de Vargas C, Narayan Yadav S, Milligan AJ, Haggblom M, et al. Membrane lipids of symbiotic algae are diagnostic of sensitivity to thermal bleaching in corals. Proc Natl Acad Sci U S A. 2004; 101(37):13531-5.

69. Knutson TR, McBride JL, Chan J, Emanuel K, Holland G, Landsea C, et al. Tropical cyclones and climate change. Nat Geosci. 2010;3(3):157-63.

70. Sobel AH, Camargo SJ, Hall TM, Lee C-Y, Tippett MK, Wing AA. Human influence on tropical cyclone intensity. Science. 2016;353(6296):242.
Ready to submit your research? Choose BMC and benefit from:

- fast, convenient online submission

- thorough peer review by experienced researchers in your field

- rapid publication on acceptance

- support for research data, including large and complex data types

- gold Open Access which fosters wider collaboration and increased citations

- maximum visibility for your research: over $100 \mathrm{M}$ website views per year

At $\mathrm{BMC}$, research is always in progress.

Learn more biomedcentral.com/submissions 